\title{
FLIGHT RECONSTRUCTION OF THE MARS PATHFINDER DISK-GAP-BAND PARACHUTE DRAG COEFFICIENT
}

\author{
by \\ Prasun N. Desai * \\ NASA Langley Research Center, Hampton, VA 23681 \\ John T. Schofield** and Michael E. Lisano \\ Jet Propulsion Laboratory, Pasadena, CA 91109
}

On July 4, 1997, the Mars Pathfinder (MPF) mission successfully landed on Mars. The entry, descent, and landing (EDL) scenario employed the use of a Disk-Gap-Band parachute design to decelerate the Lander. Flight reconstruction of the entry using MPF flight accelerometer data revealed that the MPF parachute decelerated faster than predicted. In the summer of 2003, the Mars Exploration Rover (MER) mission will send two Landers to the surface of Mars arriving in January 2004. The MER mission utilizes a similar EDL scenario and parachute design as that employed by MPF. As a result, characterizing the degree of underperformance of the MPF parachute system is critical for the MER EDL trajectory design. This paper provides an overview of the methodology utilized to estimate the MPF parachute drag coefficient as experienced on Mars.

\section{$\underline{\text { Nomenclature }}$}

AGL

DGB

$\mathrm{E}$

EDL

MER

MGS

MPF

$\mathrm{A}_{\text {Par }}$

$\mathrm{A}_{\mathrm{B} / \mathrm{S}}$

$\mathrm{A}_{\text {Lan }}$

$\mathrm{C}_{\mathrm{D}}$

$\mathrm{C}_{\mathrm{D}_{\text {Par }}}$

$\mathrm{C}_{\mathrm{D}_{\mathrm{B} / \mathrm{S}}}$

$\mathrm{C}_{\mathrm{D}_{\text {Lan }}}$

$\mathrm{F}_{\mathrm{B}}$

$\mathrm{F}_{\mathrm{D}}$

$\mathrm{g}$

$\mathrm{H}$

Lat

Lon

Above Ground Level
Disk-Gap-Band
Entry
Entry, Descent, and Landing
Mars Exploration Rover
Mars Global Surveyor
Mars Pathfinder
Parachute Area
Backshell Area
Lander Area
Drag Coefficient
Parachute Drag Coefficient
Backshell Drag Coefficient
Lander Drag Coefficient
Buoyancy Force
Drag Force
Gravitational Acceleration
Scale Height
Latitude
Longitude

\footnotetext{
* Senior Aerospace Engineer, Aerospace Systems, Concepts and Analysis Competency; p.n.desai@larc.nasa.gov, Senior Member AIAA. * Principal Scientist, Earth and Space Sciences Division; John.T.Schofield@jpl.nasa.gov.

$\ddagger$ Supervisor, Mission Analysis Software Engineering Group; Michael.E.Lisano@jpl.nasa.gov.
}

$\begin{array}{ll}\text { Ls } & \text { Solar Longitude } \\ \text { LTST } & \text { Local True Solar Time } \\ \mathrm{m} & \text { Suspended Mass } \\ \mathrm{M} & \text { Molar Weight } \\ \rho & \text { Atmospheric Density } \\ \mathrm{P} & \text { Pressure } \\ \mathrm{T} & \text { Temperature } \\ \mathrm{V} & \text { Velocity } \\ \text { Vm } & \text { Molar Volume } \\ \text { Vol } & \text { Lander Volume } \\ \mathrm{W} & \text { Weight } \\ \mathrm{Z} & \text { Altitude }\end{array}$

\section{Background}

On July 4, 1997, the Mars Pathfinder (MPF) mission successfully landed on Mars. The entry, descent, and landing (EDL) scenario employed by the mission is shown in Fig. 1. Mars Pathfinder utilized numerous methods for decelerating the Lander during the entry. Early in the descent, the Lander was decelerated solely by the use of aerodynamic drag generated by the capsule forebody. At approximately $8.6 \mathrm{~km}$ altitude, a parachute was deployed to further decelerate the Lander during the descent. Approximately at $15 \mathrm{~m}$ above ground level (AGL), retrorockets were fired to remove any remaining velocity at which point the Lander was released. Prior to Lander release, airbags were inflated around the Lander to cushion it during ground impact. References 1 gives an 
overview of the Mars Pathfinder mission, as well as, a description of the EDL events.

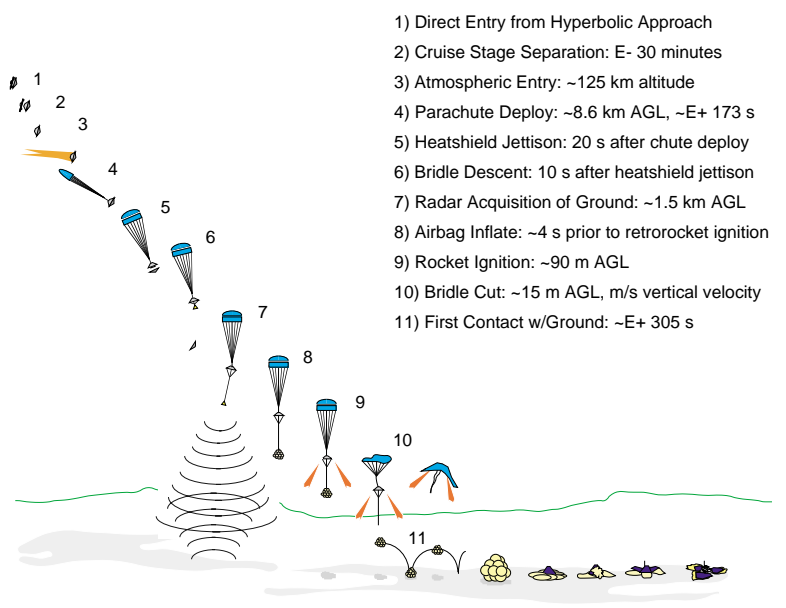

Figure 1. MPF Entry, Descent, and Landing Sequence of Events.

The Pathfinder mission utilized a Disk-Gap-Band (DGB) parachute design to provide deceleration during the terminal phase of the entry. The DGB parachute used by MPF was a derivative of that flown on the Viking missions. ${ }^{2}$ Reference 3 provides a description of the design and development of the MPF parachute system.

Flight reconstruction of the entry using MPF flight accelerometer data revealed that Pathfinder decelerated faster than predicted based on the estimated value of the MPF parachute $C_{D}$ of 0.50 ; a value which was determined from low altitude Earth flight tests and wind tunnel data during the development of the MPF parachute (see Ref. 3). An explanation of this underperformance of the MPF parachute system from that which was predicted is still not known.

In the summer of 2003, the Mars Exploration Rover (MER) mission will launch two Landers that arrive at Mars in January 2004. The MER mission utilizes a similar EDL scenario and parachute design as that employed by MPF. Therefore, characterizing the degree of underperformance of the MPF parachute system is critical for the MER mission, since the parachute drag coefficient $\left(\mathrm{C}_{\mathrm{D}}\right)$ is a driver for the MER entry, descent, and landing trajectory design. As a result, a good estimate of the MPF parachute $C_{D}$ as experienced at Mars is needed, along with a measure of its uncertainty in order to robustly design the MER EDL phase of the mission. This investigation was initiated to determine the best possible flight reconstruction estimate for the MPF parachute $C_{D}$ as exhibited on Mars. All data sources required for calculation of the parachute $C_{D}$ are reexamined. In addition, an overview of the methodology utilized in this reexamination of the MPF parachute $C_{D}$ estimate is provided.

\section{$\underline{\text { Approach }}$}

At the terminal velocity condition, the sum of the vehicle drag force $\left(F_{D}\right)$ and the buoyancy force $\left(F_{B}\right)$ equal the weight of the vehicle (W)

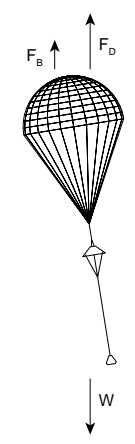

$$
\begin{aligned}
& \mathrm{W}=\mathrm{mg} \\
& \mathrm{F}_{\mathrm{B}}=\rho \mathrm{g} \text { Vol } \\
& \mathrm{F}_{\mathrm{D}}=\rho \mathrm{v}^{2}\left(\mathrm{C}_{\mathrm{D}_{\mathrm{Par}}} \mathrm{A}_{\mathrm{Par}}+\mathrm{C}_{\mathrm{D}_{\mathrm{B} / \mathrm{S}}} \mathrm{A}_{\mathrm{B} / \mathrm{S}}+\mathrm{C}_{\mathrm{D}_{\text {Lan }}} \mathrm{A}_{\text {Lan }}\right) / 2
\end{aligned}
$$

where

$\mathrm{m}=$ suspended mass,

$\mathrm{g}=$ gravitational acceleration

$\rho=$ atmospheric density,

$\mathrm{Vol}=$ total vehicle volume

$\mathrm{v}=$ terminal velocity,

$\mathrm{C}_{\mathrm{D}_{\mathrm{B} / \mathrm{S}}}=$ Backshell drag coefficient,

$\mathrm{A}_{\mathrm{B} / \mathrm{S}}=$ Backshell reference area

$\mathrm{C}_{\mathrm{D}_{\text {Lan }}}=$ Lander drag coefficient,

$\mathrm{A}_{\mathrm{Lan}}=$ Lander Reference area

$\mathrm{C}_{\mathrm{D}_{\text {Par }}}=$ Parachute drag coefficient,

$\mathrm{A}_{\text {Par }}=$ Parachute reference area

Equating the forces and substituting for the parameter yields the equation for predicting the parachute $C_{D}$

$$
\begin{aligned}
\mathrm{C}_{\mathrm{D}_{\text {Par }}=} & 2(\mathrm{mg}-\rho \mathrm{gVol}) /\left(\rho v^{2} \mathrm{~A}_{\text {Par }}\right)-\mathrm{C}_{\mathrm{D}_{\mathrm{B} / \mathrm{S}}} \mathrm{A}_{\mathrm{B} / \mathrm{S}} / \mathrm{A}_{\text {Par }} \\
& -\mathrm{C}_{\mathrm{D}_{\text {Lan }}} A_{\text {Lan }} / A_{\text {Par }}
\end{aligned}
$$

Note, the velocity and density are the largest contributors for determining $C_{D_{\text {Par }}}$, since the velocity term appears to the second power in the equation, and any uncertainty in density will directly relate to an uncertainty in $C_{D_{\text {Par }}}$ because density and $C_{D}$ are coupled together for determining drag. Hence, an accurate estimate for both parameters is necessary. 
All parameters required for calculation of the parachute $C_{D}$ are reexamined: MPF altimeter flight data, atmospheric properties, Backshell and Lander $C_{D}$ values, parachute area, and total vehicle volume. Values for the parameters are updated where appropriate. Specifically, outlined is the rationale for the improvement in the estimates for the value of the terminal velocity and atmospheric properties, which are the largest contributors to the parachute $C_{D}$ estimate. Note, conservative assumptions are utilized where appropriate.

To estimate the MPF parachute $C_{D}$ value, this investigation employs the use of a Monte Carlo technique. In so doing, uncertainties in all the parameters can be included in the analysis. As a result, a statistical range on the MPF parachute $C_{D}$ can be defined. With this approach, a more rigorous methodology is employed which provides for the best possible flight reconstruction estimate for the MPF parachute $\mathrm{C}_{\mathrm{D}}$.

\section{$\underline{\text { Atmospheric Density Determination }}$}

Accurate density estimation is necessary for determining the parachute $C_{D}$, since the two parameters are coupled. However, neither density, pressure, nor temperature were measured during the MPF parachute descent.

Density can be derived through temperature and pressure measurements. Accurate MPF temperature and pressure measurements are available at the surface (altitude of $1 \mathrm{~m}$ ). However, measurements are required above the surface near terminal velocity conditions. Therefore, surface pressure and temperature must be extrapolated to the altitude where $C_{D}$ is derived. Pressure can be extrapolated accurately, however, temperature must be derived from models or other measurements. The corresponding density can then be calculated by extrapolating the pressure and temperature, which were measured at $1 \mathrm{~m}$. The temperature increases rapidly with altitude from the surface over the lower few hundred meters. However, considerable uncertainty exists for extrapolating the temperature from the surface to higher altitudes due to the uncertainty in the width of the temperature inversion layer.

Therefore, current atmospheric property estimates are supplemented by Mars Global Surveyor (MGS) radio-occultation data. ${ }^{4}$ See Appendix for a detailed description on the rationale. Current best estimate of MPF parachute $C_{D}$ is performed at an altitude of $1 \mathrm{~km}$. The temperature at $1 \mathrm{~km}$ is taken from profiles derived from MGS radio-occultation measurements. High vertical resolution profiles from the surface to $30 \mathrm{~km}$ are obtained near the Pathfinder season, local time, and location, but for the following Mars year. The profiles show a maximum temperature of $220 \mathrm{~K}$ at $1 \mathrm{~km}$ with little day-to-day variation. This estimate is based on the assumption that year-to-year temperature variability at 1 $\mathrm{km}$ is small.

The year-to-year temperature variability at $1 \mathrm{~km}$ is well within $\pm 9 \mathrm{~K}(3-\sigma)$ error assumed. Multi-year radiooccultation measurements are not available for the MPF conditions. However, MGS Thermal Emission Spectrometer (TES) data show little year-year variability in mean $0-10 \mathrm{~km}$ temperature at other seasons. Multi-year TES coverage of the MPF season are not yet available, although, Viking and MPF Landers demonstrate that surface pressure varies little from year-to-year. However, due to the lack of accurate temperature data, a uniform distribution for the temperature variation is utilized in the analysis for conservatism, rather than a normal distribution which is more consistent with the observed temperature data.

The assumptions outlined in this investigation regarding the atmospheric properties were independently reviewed. The approach taken is consistent with known modeling constraints and uncertainties. Overall, the approach developed is the best that can be constructed with the available data to define the atmospheric properties during the MPF parachute descent.

\section{Terminal Velocity Determination}

The MPF altimeter flight data was reexamined using higher order filtering techniques beyond that performed in the early reconstruction efforts ${ }^{5}$. The current investigation performs two independent filtering techniques in an effort to smooth the MPF altimeter flight data to obtain a more accurate determination of the terminal velocity. A Butterworth filter and a more sophisticated Kalman filter were utilized on the flight data.

The Kalman filter (actually a backward-in-time filter plus a forward-in-time smoother) was designed to process data simultaneously from the MPF 3-axis accelerometer and the radar altimeter data. Nine parameters were estimated in the filter. These were: height above the ground, horizontal distance from the touchdown point, vertical and horizontal speed relative to the ground, vertical and horizontal non-conservative (i.e. drag) acceleration components and the time derivatives of these accelerations, and the angle between the MPF Lander base petal and the vertical direction. 
The filter was first run backwards in time over the accelerometer and radar data set, from a point in time just prior to firing of the MPF retrorockets, to the time of the first radar measurement (a time span of approximately 20 seconds). The filter state vector was initialized by integrating the accelerometer data backwards in time, assuming a constant gravitational acceleration. The backward-in-time sequence of events included the initial impact with the ground, the free-fall of the Lander, the severing of the MPF bridle connecting the Lander with Backshell and parachute, and the firing of the retrorockets. A large covariance was used for the backward-in-time filter pass.

Subsequently, the forward-in-time filter was initialized with the state vector of the backward-in-time filter, taken at the first radar measurement time. The state vector histories verses time of the forward and backward filters were averaged to produce the smoothed estimated state. The measurement residuals computed with the smoothed state had essentially zero bias, and RMS values of 1.47 meters for the altimeter measurements, and approximately 0.05 Earth g's per axis for the accelerometer measurements. One component of the smoothed estimated state, the vertical velocity, is shown in Figs. 2 and 3.

The two different filtering techniques show a good agreement in the mean value for the terminal velocity as seen in Figs. 2 and 3. In addition, as a by-product of the Kalman filtering technique, a statistical estimate on the uncertainty in the terminal velocity is obtained of \pm 1.8 $\mathrm{m} / \mathrm{s}(3-\sigma)$. This uncertainty estimate can be directly used in the Monte Carlo approach for specifying a dispersion on the terminal velocity.

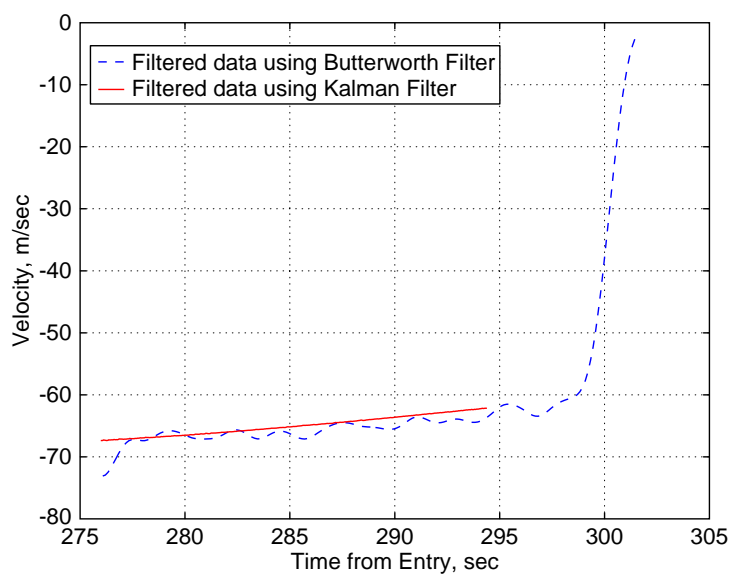

Figure 2. MPF Terminal Velocity Estimate using Filtering Techniques

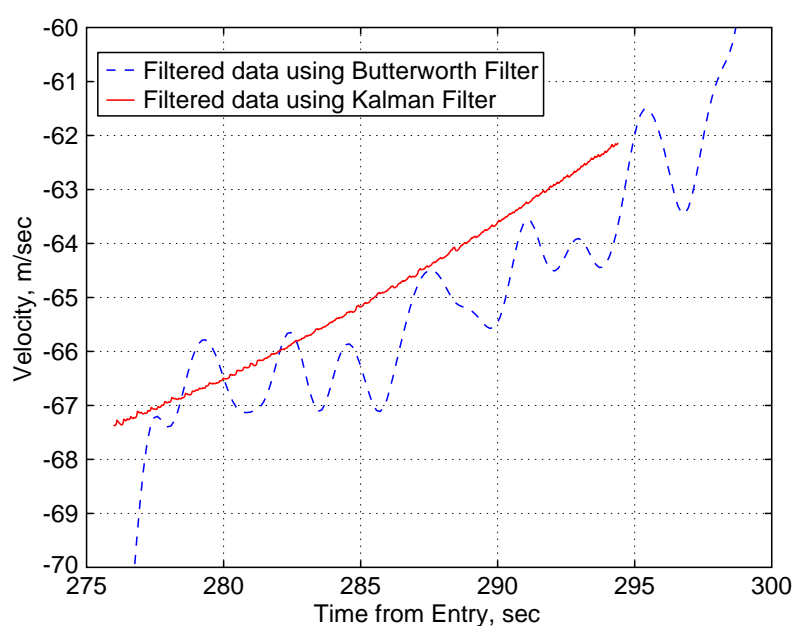

Figure 3. MPF Terminal Velocity Estimate using Filtering Techniques (zoomed in).

\section{$\underline{\text { Other Parameters }}$}

The MPF parachute area (of the flight unit) was a quantity that was not explicitly measured. Unfortunately, there was no requirement to control the actual MPF canopy area. As a result, its exact value is unknown. Since the parachute area is a quantity that directly affects the value of the parachute $C_{D}$, an accurate knowledge is required to calculate the value of the MPF parachute $\mathrm{C}_{\mathrm{D}}$.

To improve the knowledge of the MPF canopy area, Pioneer Aerospace (developers of the MPF parachute system) measured the area of existing MPF qualification parachutes. The flight and qualification parachutes were manufactured at the same time from the same lot of material. Hence, the final dimensions should be very similar. From these measurements, a mean value of the MPF parachute area and its variation were determined. This variation in parachute area was taken into account as part of the Monte Carlo methodology in determining the range on the MPF parachute $C_{D}$ value.

The values for the Backshell $C_{D}$ and Lander $C_{D}$ were also updated based on wind tunnel tests preformed at the ViGYAN low speed facility in Hampton, Virigina. ${ }^{6}$ The tests improved the knowledge in the $C_{D}$ values of both configurations.

\section{$\underline{\text { Results }}$}

Based on the reexamination of all the parameters described, the MPF parachute $C_{D}$ value is determined using a Monte Carlo analysis. The list of parameters 
included in the analysis is given in Table 1, along with their mean value and uncertainty range.

Using the specified distributions, 1000 random values were statistically sampled for each parameter within its uncertainty range. These values for all the parameters were then substituted in Eqn. (4) to determine an estimate for the MPF parachute $C_{D}$.

The resulting distribution in atmospheric density (using the procedure outlined in the Appendix) arising from the variation in atmospheric temperature and pressure is shown in Fig. 4. A variation of approximately $\pm 6 \%$ is observed about the mean density. The resulting distribution in the value of the
MPF parachute $C_{D}$ arising from the variation in all the parameters is shown in Fig. 5. A mean value of 0.41 is calculated for the MPF parachute with a $3-\sigma$ uncertainty of $\pm 0.05( \pm 12 \%)$. A majority of this dispersion in the MPF parachute $C_{D}$ value is due to the uncertainty in the atmospheric density. The actual dispersion in the $C_{D}$ of a parachute is likely to be smaller than this range. However, due to the uncertainty in the atmospheric properties, a smaller range in the MPF parachute $C_{D}$ value is not possible. The minimum value obtained for the MPF parachute $C_{D}$ is 0.36 . Note, in obtaining this revised prediction, conservative assumptions were utilized where appropriate.

Table 1. Parameters included in Monte Carlo analysis.

\begin{tabular}{|c|c|c|c|}
\hline Parameter & Mean & Distribution & Uncertainty Range \\
\hline $\mathrm{m}, \mathrm{kg}$ & 520.9 & - & - \\
\hline $\mathrm{g}, \mathrm{m} / \mathrm{s}^{2}$ & 3.7245 & - & - \\
\hline $\mathrm{A}_{\mathrm{B} / \mathrm{S}}, \mathrm{m}^{2}$ & 5.39 & - & - \\
\hline $\mathrm{A}_{\text {Lan }}, \mathrm{m}^{2}$ & 1.76 & - & - \\
\hline $\mathrm{A}_{\mathrm{Par}}, \mathrm{m}^{2}$ & 127.6 & Gaussian & $\pm 5 \%(3-\sigma)$ \\
\hline Vol, $\mathrm{m}^{3}$ & 135 & uniform & $\pm 20 \%$ \\
\hline $\mathrm{C}_{\mathrm{D}_{\mathrm{B} / \mathrm{S}}}$ & 1.33 & uniform & $\pm 5 \%$ \\
\hline $\mathrm{C}_{\mathrm{D}_{\text {Lan }}}$ & 1.072 & uniform & $\pm 5 \%$ \\
\hline Temperature, $\mathrm{K}$ & 221 & uniform & \pm 9 \\
\hline Surface Pressure, mbar & 6.76 & uniform & \pm 0.15 \\
\hline $\mathrm{v}, \mathrm{m} / \mathrm{s}$ & 65.5 & Gaussian & $\pm 1.8(3-\sigma)$ \\
\hline
\end{tabular}

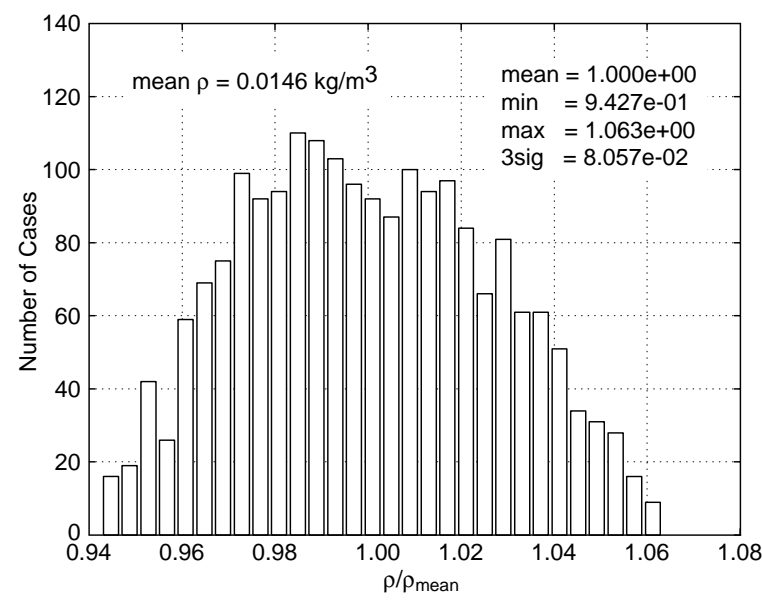

Figure 4. Distribution in the Mean Atmospheric Density

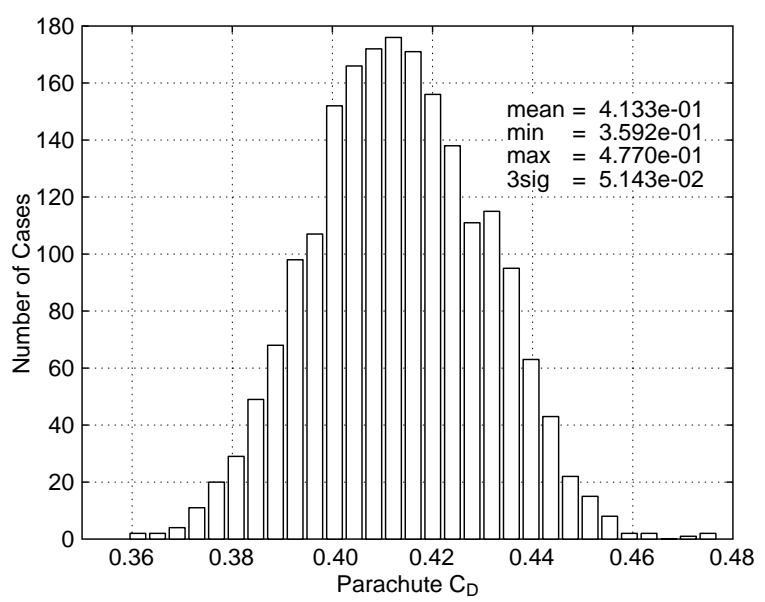

Figure 5. Distribution in the MPF Parachute $C_{D}$ value 


\section{Conclusions}

Based on the assumptions presented and reexamination of all the parameters (additional filtering of MPF radar altimeter data, revised atmospheric property estimates, and updated parachute area and Backshell and Lander $C_{D}$ values), a revised flight reconstructed mean value for the MPF parachute $C_{D}$ of 0.41 is obtained with a $3-\sigma$ uncertainty of $\pm 0.05( \pm 12 \%)$. A majority of this variation in the MPF parachute $C_{D}$ value is due to the uncertainty in the atmospheric density. In obtaining this revised prediction, conservative assumptions were utilized where appropriate.

The largest contributor to uncertainty in the MPF parachute $C_{D}$ is uncertainty in density and the terminal velocity. Reexamination of the radar altimeter flight data allows for a better estimate on the terminal velocity and its uncertainty. In addition, re-examination of the atmospheric properties, supplemented by additional data, allows for a better estimate on the density and its uncertainty. Furthermore, the use of the Monte Carlo technique statistically allows for incorporation of uncertainties on all the parameters to better assess the variation in the MPF parachute $C_{D}$ value.

\section{$\underline{\text { Acknowledgements }}$}

The portion of research described in this paper that was carried out at the Jet Propulsion Laboratory, California Institute of Technology, was performed under a contract with the National Aeronautics and Space Administration.

\section{$\underline{\text { References }}$}

1) Spencer, D. A. and Bruan, R. D., "Mars Pathfinder Atmospheric Entry: Trajectory Design and Dispersion Analysis," The Journal of Spacecraft and Rockets, Vol. 33, No. 5, September-October 1996, pp. 670676.

2) Lau, R. A. and Husson, J. C., "The Viking Mars Lander Decelerator System," AIAA Paper 70-1162, 1970.

3) Fallon, E. J., "System Design Overview of the Mars Pathfinder Parachute Decelerator Subsystem, AIAA Paper 97-1511, 1997.

4) Dallas, S., "The Mars Global Surveyor Mission," 1997 IEEE Aerospace Conference Proceedings, Inst. Of Electrical and
Electronic Engineers, New York, 1997, pp. 173-179.

5) Witkowski, A., "Mars Pathfinder Parachute System Performance," AIAA Paper 991701, 1999.

6) Dominguez, K., Graham, A. B., and DeLoach, R. "Development of an MDOE Compliant Control System in the ViGYAN Low-Speed Wind Tunnel," AIAA Paper 2001-0169, January 2001.

\section{Appendix: Density Estimation Procedure}

In order to revise the Pathfinder parachute $C_{D}$ calculation during descent, an accurate prediction of the density of the atmosphere at some level near the surface is necessary, where the Pathfinder Lander is falling close to its terminal velocity. Density can be obtained from direct measurements, or can be inferred from measurements of pressure and temperature using Eqn. (A-1).

The atmospheric density profile was derived from Pathfinder accelerometer measurements down to an altitude of just below $9 \mathrm{~km}$, where the parachute deployed. Accurate measurements of surface pressure and temperature at $1 \mathrm{~m}$ were made immediately after landing, and at the same local time on subsequent days at the landing site. Unfortunately, no high quality temperature and pressure measurements were taken during parachute descent.

In the original approach, an attempt was made to calculate the density at $300 \mathrm{~m}$ (altitude prior to airbag inflation) by extrapolating temperature and pressure from the known conditions at the surface. Pressure can be extrapolated fairly accurately using the hydrostatic equation (Eqs. (A-2) \& (A-3)). To extrapolate temperature, results were used from a 1-D boundary layer model calculated for Pathfinder conditions, and which were shifted by a few degrees to agree with the $201.5 \mathrm{~K}$ Pathfinder measurement at $1 \mathrm{~m}$.

Models show that for the Pathfinder landing conditions $\left(\mathrm{Ls}=143^{\circ}, \mathrm{LTST}=03: 00\right.$, Lat $=19.5^{\circ} \mathrm{N}$, Lon $\left.=33.5^{\circ} \mathrm{W}\right)$, atmospheric temperature should increase from a minimum at the surface to a maximum at roughly $1 \mathrm{~km}$, before falling with increasing altitude. There is considerable uncertainty in the width of the inversion layer below $1 \mathrm{~km}$, so that the temperature extrapolation to $300 \mathrm{~m}$ might be subject to significant error. 
MGS obtained radio occultation temperature profiles near the Pathfinder season, local time, and location, but for the following Mars year. These profiles have a vertical resolution of $0.5-1.0 \mathrm{~km}$, are accurate in the lower atmosphere, but do not extend completely to the surface. Four profiles selected within the bin Ls $=139.9^{\circ}-141.4^{\circ}$, LTST $=04: 11$, Lat $=16.5^{\circ}-20.9^{\circ} \mathrm{N}$, Lon $=26.6^{\circ}-42.8^{\circ} \mathrm{W}$, are consistent with each other to a few $\mathrm{K}$ below $10 \mathrm{~km}$ and show near surface temperature peaks of $220 \mathrm{~K}$ near $1 \mathrm{~km}$ altitude.

The MGS radio-occultation data suggested a new approach. Densities calculated near $1 \mathrm{~km}$ (the atmospheric temperature peak) are less sensitive to vertical gradients, and can be based on reliable radiooccultation temperature measurements. The recommended density calculation utilized in this analysis is summarized as follows:

1. Derive $\rho(z)$ from $P(z)$ and $T(z)$ at $1 \mathrm{~km}$, using Eqn. (A-1) .

2. Based on the occultation data, $\mathrm{T}(\mathrm{z})=221 \mathrm{~K}$, $\pm 3 \mathrm{~K}(1-\sigma)$ at $1 \mathrm{~km}$.

3. $\mathrm{P}(\mathrm{z})$ at $1 \mathrm{~km}$ is derived from Eqs. (A-2) \& (A-3).

Given: Ps $=6.76 \pm 0.05$ mbar $(1-\sigma)$ from Pathfinder (Eqn. (A-2)). $\mathrm{T}=215 \mathrm{~K}$ in Eqn. (A-3).

Note: $\mathrm{T}$ is the mean temperature from $0-1 \mathrm{~km}$, which is probably weighted more towards the $1 \mathrm{~km}$ than the $1 \mathrm{~m}$ temperature because the surface temperature inversion is significantly narrower than $1 \mathrm{~km}$. The consequences of this are not very significant in the pressure calculation.

From the ideal gas law, the density at altitude $\mathrm{z}$ $\mathrm{km}$ in Mars' atmosphere is given by the expression:

$$
\rho(\mathrm{z})=[\mathrm{P}(\mathrm{z}) / \mathrm{P} 0] *[\mathrm{~T} 0 / \mathrm{T}(\mathrm{z})] *[\mathrm{M} / \mathrm{Vm}]
$$

where

$$
\begin{aligned}
& \rho(z) \text { is the density at altitude } \mathrm{z} \text { in } \mathrm{gm} / \mathrm{cm}^{3} \\
& \mathrm{P}(\mathrm{z}) \text { is the pressure at altitude } \mathrm{z} \text { in mbars } \\
& \mathrm{T}(\mathrm{z}) \text { is the temperature at altitude } \mathrm{z} \text { in Kelvin } \\
& \mathrm{P} 0=1013.24 \text { mbar (Standard Pressure) } \\
& \mathrm{T} 0=273.15 \mathrm{~K} \text { (Standard Temperature) } \\
& \mathrm{M}=43.5 \mathrm{gm} \text { (Mean atmospheric molar weight) } \\
& \mathrm{Vm}=2.241 \mathrm{e}+4 \mathrm{~cm}^{3} \text { (Molar volume at STP) }
\end{aligned}
$$

Given $P(z)$ and $T(z)$ the density can be calculated Eqn. (A-1). T(z) at the level of interest must be specified. Provided $\mathrm{z}<2 \mathrm{~km}, \mathrm{P}(\mathrm{z})$ can be extrapolated from the surface using the expression:

$$
\mathrm{P}(\mathrm{z})=\mathrm{Ps} * \operatorname{Exp}(-\mathrm{z} / \mathrm{H})
$$

where

Ps is Surface Pressure

$\mathrm{H}$ is the mean atmospheric pressure scale height in $\mathrm{km}$

$\mathrm{H}$ is approximated by the expression:

$$
\mathrm{H}=\mathrm{RT} /(\mathrm{Mg})
$$

where

$$
\begin{aligned}
& \mathrm{R}=8.314 \mathrm{~J} / \mathrm{K} / \text { Mole (The gas constant) } \\
& \mathrm{T}=\text { Mean temperature from } 0-\mathrm{z} \mathrm{km} \text { (need not be } \\
& \text { very accurate) } \\
& \mathrm{M}=43.5 \mathrm{gm} \text { (Mean molar weight as in Eqn. (A-1)) } \\
& \mathrm{g}=\begin{array}{l}
3.717 \mathrm{~m} / \mathrm{s}^{2} \text { (Acceleration due to gravity at } \\
\text { surface) }
\end{array}
\end{aligned}
$$

